\title{
MENINGENCEFALITE A ASPERGILLUS
}

\author{
EHRENFRIED O. WITTIG * \\ IZRAIL CAT ** \\ GILDA KASTING ***
}

O gênero Aspergillus apresenta algumas espécies patogênicas a vegetais, insetos, pássaros, animais domésticos e ao homem. Neste, a infeç̧ão é mais comum em adultos, com pequeno predomínio no sexo masculino, acometendo freqüentemente os trabalhadores que tem contacto com vegetais ou sementes secas, que são seus habitats preferidos. Os Aspergillus são os mais comuns $\mathrm{e}$ incômodos fungos contaminantes encontrados em laboratórios (Conant $\mathrm{e}$ col. ${ }^{2}$ ). A relação entre o seu achado laboratorial e a eventual patologia do paciente é sempre de difícil avaliação. As espécies mais freqüentemente patogênicas ao homem são o $A$. niger, $A$. nidulares, A. amstelodami, A. flavus, $A$. orizae, $A$. sydowi e, o mais habitual no sistema nervoso, o $A$. fumigatus. A aspergilose tem sido encontrada em todos os órgãos humanos, destacando-se os ouvidos, pulmões, seios paranasais, regiões orbitárias, pele, ocasionalmente o sistema nervoso central, coração e rins ${ }^{1,4,5,6,7}$. O primeiro caso de aspergilose do sistema nervoso foi relatado por Oppe em 1897. No Brasil não encontramos referências na literatura consultada. A doença pode ser localizada ou disseminada, sendo sua via de introdução mais freqüente, o aparelho respiratório. $\mathrm{Na}$ forma disseminada ou septicêmica as lesões neurológicas estão presentes em 50 a $60 \%$ dos casos. Já foram referidas manifestações encefálicas, meningíticas e medulares, porém sem características próprias, mas freqüentemente acompanhadas de sinais infecciosos.

\section{OBSERVACAO}

J.C.G., sexo masculino, branco, com 39 dias de idade, residente em Curitiba, Internado no Departamento de Pediatria em 07-09-1963 (R.G. 551.184). História clinica - Doença iniciada há 4 dias com obstrução nasal, crises de soluços e tosse seca. O paciente permaneceu com este quadro durante 3 dias quando houve agravamento com hipertermia, irritabilidade, taquipnéia, respiração gemente, movimentos de lateralidade da cabeça e recusa de alimentação. Há 8 dias apresentou uma evacuação semi-liquida em pequena quantidade, de coloração esverdeada. Antecedentes sem particularidades. Exame físico geral - Freqüência cardíaca de 140 bpm; respiraçāo em $42 \mathrm{mpm}$; temperatura de $38,5^{\circ} \mathrm{C}$; peso $3.250 \mathrm{gr}$; perímetro cefálico de $36 \mathrm{~cm}$; perímetro toráxico de $33 \mathrm{~cm}$; estatura de $51 \mathrm{~cm}$; sonolência com periodos

Faculdade de Medicina, Universidade Federal do Paraná: * Auxiliar de Ensino de Neurologia; * Professor Adjunto de Pediatria; *** Professor Assistente de Patologia. 
de agitação psicomotora; cianose peri-oral; lesões difusas eritematocrostosas, com descamação lamelar; fontanelas normais; induto esbranquiçado no orofaringe; figado a $2 \mathrm{~cm}$ do rebordo costal e baço palpável. Reflexo de Moro hiperativo; hipertonia generalizada inclusive de nuca; midríase; reflexo fotomotor diminuido. Exames complementares - Liquido céfalorraqueano: células $20 / \mathrm{mm}^{3}$; proteínas $20 \mathrm{mg} \%$; glicose $58 \mathrm{mg} \%$; cloretos $735 \%$; Hemograma: hemácias $2.780 .000 \mathrm{~mm}^{3}$; $\mathrm{Hgb}_{5,9 \%}$; leucócitos $11.400 \mathrm{~mm}^{3}$ (linfócitos $31 \%$; monócitos $9 \%$; bastonetes 23\%; segmentados $37 \%)$; plaquetas normais. Sódio plasmáticos $127,2 \mathrm{mEq} / 1$; Glicemia $42 \mathrm{mg} \%$. Eletrocardiograma: taquicardia sinusal; discreta sobrecarga ventricular. Cultura de secreção de abscessos: diplococcus gram-positivos e estafilococcos. Proteinas totais no sangue: $4,1 \mathrm{~g} \%$; Radiografia de tórax: condensaçăo de ambas as bases. Sódio plasmático: $137,5 \mathrm{mEq} / 1$ (2 horas antes do óbito). Exames post-mortem - glicemia $180 \mathrm{mg} \%$; Uréia $85 \mathrm{mg} \%$; Fosfato inorgânico $6,7 \mathrm{mg} \%$; Fosfatase alcalina 1,3 U.B. Cálcio $9,6 \mathrm{mg} \%$; Proteínas totais 2,7 $\mathrm{g} \%$. Medicacão - Durante o período de internação o paciente foi medicado com penicilina, cloranfenicol, eritromicina, nistatina, cortrofina $\mathrm{Z}$, oxacilina, dexametazona, barbitúricos, hidantoinatos, gama-globulina, complexos vitamínicos e hidratação. Evolução: Nos primeiros dias de internação surgiram náuseas e vômitos, com persistência dos períodos de sonolência, irritabilidade, taquicardia, taquipnéia e aumento de volume hepático. A partir do $6 .^{\circ}$ dia de internação, o paciente apresentou diarréia, hipertermia, acentuação da palidez cutânea. No $100^{\circ}$ dia surgiu moderada ictericia e tumoração dolorosa no apêndice xifóide e no terço inferior do braço; com sinais inflamatórios, de onde foi drenada grande quantidade de secreção purulenta amarelada e espessa. As bulhas cardiacas tornaram-se hipofonéticas e aumentou o inducto esbranquicado na cavidade bucal. No 15.0 dia apresentou hipotonia, movimentos involuntários do segmento cefálico, com desvio de olhos e da rima labial para a direita, estertores subcrepitantes em ambos os hemitoraces e aumento de volume do membro superior direito e membro inferior esquerdo, com calor local. Estado geral máu e fontanela anterior tensa. Nos últimos dias apresentou crises convulsivas à direita, bradicardia, arritmia cardiaca, secreção sanguinolenta na cavidade bucal, edema generalizado, coma vigil, taquipnéia com respiracão gemente, períodos de apnéia e cianose. No 26..$^{3}$ dia ocorreu parada respiratória seguida de parada cardiaca.

Necrópsia - Conjuntivas sub-ictéricas; edema generalizado; abscessos múltiplos ao nível do braço, mão, face, abdomen e apêndice xifóide, o qual se comunica com a cavidade toráxica e o lobo inferior do pulmão direito. Pulmões evidencianı pneumonia estafilocócica e pleurite fibrino-purulenta. Hepatomegalia colestática e esplenomegalia congestiva, septicêmica. Enterocolite exucerativa bacteriana. Cérebro com aumento de peso, contendo substância de aspecto purulento, destruindo quase todo o hemisfério cerebral direito e o tronco cerebral, comunicando-se com o ventrículo lateral direito. As leptomeninges deste lado se apresentam espessadas e com aspecto leitoso. O restante do parênquima encefálico mostra áreas punctiformes, esparsas, de hemorragia e necrose. Microscopicamente o cérebro mostra edema, congestão e presença de múltiplas áreas de hemorragias e necrose, de várias dimensões e zona de intensa abscedação, onde se observam numerosos fungos, constituidos de filamentos ou hifas com septaçōes escuras, que se bifurcam em ângulo agudo na maioria das vezes (gênero Aspergillus). As leptomeninges mostram-se espessadas, com edema, infiltrado neutrofilico denso e colônias de fungos. Esparsas pelo parênquima encefálico existem em tôrno dos vasos, numerosas hífas (Fig. 1). Não foram vistos agrupamentos bacterianos.

\section{COM ENT A R I OS}

Embora a aspergilose possa ter evolução aguda e fulminante, quase sempre se desenvolve crônicamente e suas manifestações não apresentam elementos característicos. Por ser um fungo bastante contaminante em labo- 

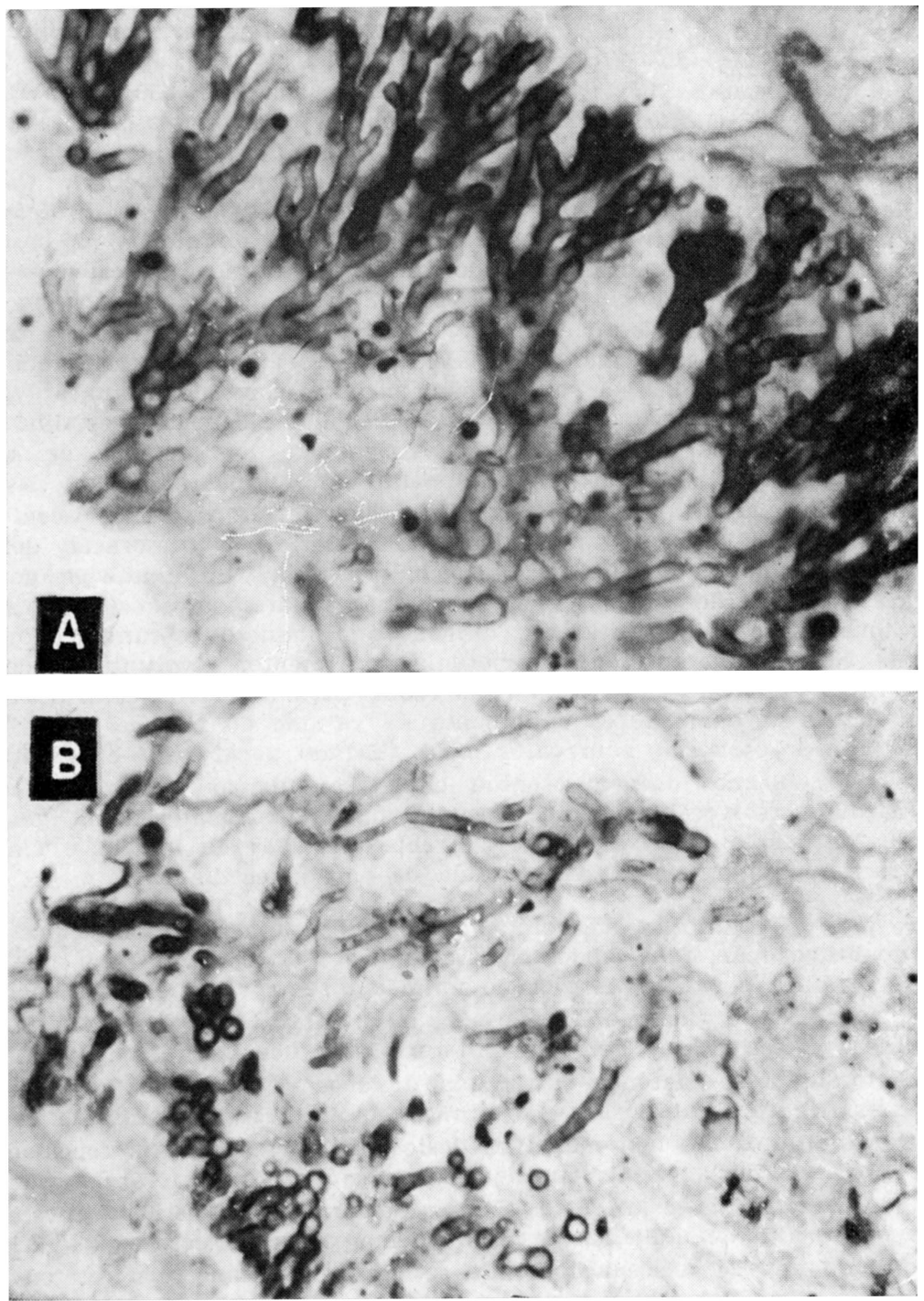

Fig. 1 - Caso J.C.G. Meningencefalite a aspergilus. Em A, hífas septadas, algumas ramificadas em ângulo agudo, com diâmetro uniforme e paredes externas paralelas, circundando área de necrose cerebral (HE 600×); em $B$, foco de necrose cerebral com esporos redondos e hifas septadas, com paredes paralelas $e$ ramificações em ângulo agudo (HE300×). 
ratório, o diagnóstico algumas vezes oferece dificuldade. Microscopicamente o processo se caracteriza pela presença de células gigantes que envolvem os filamentos miceliais, células polimorfonucleares e macrófagos, algumas vezes alterações necrotizantes, granulomatosas ou abscedantes e, ocasionalmente, calcificações; não raramente são observadas arterites trombosantes. Os filamentos miceliais em regra estão localizados ao redor ou no interior dos vasos. Os focos de hemorragias são bastante freqüentes, assim como trombose de vasos de grande e pequeno calibre. O líquido céfalorraqueano habitualmente apresenta pleocitose com predomínio de neutrófilos, a taxa de proteinas está elevada e a de glicose normal. A identificação do fungo é realizada pelas conidióforas ou hífas septadas, e deverá sempre ser diferenciada dos gêneros Penicillium, Cândida e $M$ ucor ${ }^{3}$.

Keye e Maggee ${ }^{5}$ chamaram atenção para o aumento do número de casos de aspergilose, coincidente com o surgimento de novas terapêuticas, não esquecendo os autores que atualmente são os casos melhor investigados e o número de publicações médicas bastante maior. Baker só observou casos de evolução fulminante após 1953.

O Aspergillus é um fungo oportunista estando quase sempre associado a outra patologia básica. É freqüente seu aparecimento em pacientes imunodebilitados por tuberculose, leucemia, moléstia de Hodgkin, carcinomas, bronquiectasias, desnutrição, diabete e em pacientes em uso prolongado de antibióticos, corticosteróides e drogas citostáticas, as quais possivelmente favorecem a instalação do fungo.

O mecanismo de instalação é discutivel, pois assim como algumas drogas poderiam agir estimulando a reprodução do fungo, outras atuariam inibindo o mecanismo de defesa do paciente. Sidranski e Friedmann observaram que o uso de corticoesteróides e antibióticos em animais, os tornam altamente suscetiveis a uma aspergilose pulmonar fatal. A ação estimulante direta de certos antibióticos, referida por alguns autores, é de pequena importância. Um tratamento mais efetivo, prolongando a vida de alguns destes pacientes diminui provavelmente sua resposta imunológica, facilitando a instalação do fungo. Das terapêuticas instituídas, o uso da Anfotericina B é a que tem dado resultados satisfatórios, mas inconstantes. A precocidade do tratamento é fundamental no resultado.

Nosso paciente apresentava um quadro micótico determinando meningite e abscessos encefálicos múltiplos. A evolução foi relativamente longa, com dupla infecção, talvez a estafilocócica, micótica. Embora o inícia dos processos, bacteriano pulmonar e o micótico meningencefálico, possa ter ocorrido simultâneamente é maior a possibilidade de que os fungos abrigados no pulmão penetraram na corrente circulatória localizando-se no encéfalo. As manifestações clínicas gerais decorrem da septicemia estafilocócica e a sintomatologia meningencefálica, do processo micótico.

O quadro neurológico é devido ao desenvolvimento meningo-encefálico, pela trombose micótica e abscedação, determinando áreas de necrose. Os 
focos hemorrágicos, freqüentemente encontrados em outros casos não tem ainda uma explicação defenitiva, mas poderiam ser devidos à ação de toxinas na parede vascular ou a trombose venosa. A medicação utilizada não deve ter favorecido a evolução do processo no presente caso, visto ele ter-se estabelecido anteriormente ao seu emprego.

\section{R E S U M O}

E relatado um caso de meningencefalite por Aspergillus em paciente com 39 dias de idade, sendo o diagnóstico feito mediante necrópsia. Aparentemente, este é o primeiro caso relatado no Brasil.

\section{S U M M A R Y}

Aspergillus meningoencephalitis: a case report.

A case of meningencephalitis due to Aspergillus in a 39 days-old boy is reported. The diagnosis was made by post-morten examination. It seems to be the first case of aspergiloris reported in Brazil.

\section{REFERENCIA S}

1. Bastos, C. O.; TAunay, A. E.; tiriba, A. C.; Galvão, P. A. A.; Sesso, J.; FILIPI, J.; BALLAN, N.; PUPO, A. A. \& GODOY, C. V. F. - Meningites. Rev. Ass. Med. Brasil. 16:27, 1971.

2. CONANT, N. F.; SMITH, D. T.; BAKER, R. D.; CALLAWAY, J. L. \& MARTINS, D. S. - Manual of Clinical Mycology. W. B. Saunders Co., Filadelfia, 1954.

3. FETTEH, B. F.; KLINTWORTH, G. K. \& HENDRY, W. S. - Mycoses of the Central Nervous System. The Willians e Wilkins Co., Baltimore, 1967.

4. LACAZ, C. S. - Terapêutica das Micoses. Fundo Editorial Procienx. São Paulo, 1962.

5. PEÑA, C. E. \& SALAZAR, H. - Aspergilosis en Colombia. Mycopath. Micol. Appl. 34:65, 1968.

6. PEET, M. M. - Aspergillus fumigatus infection of the cerebellum. Trans. Amer. Neurol. Assoc. 71:165, 1946.

7. TVETEN, L.; LOKEN, A. C. \& ITAUGE, T. - Aspergillosis cerebri. Acta. Chir. Scand. 130:149, 1965.

Hospital de Clinicas - Disciplina de Neurologia - 80000 Curitiba, PR - Brasil. 